\title{
Aerosol effects on clouds and precipitation during the 1997 smoke episode in Indonesia
}

\author{
H.-F. Graf, J. Yang, and T. M. Wagner \\ Centre for Atmospheric Science, University of Cambridge, Cambridge, UK \\ Received: 13 November 2007 - Published in Atmos. Chem. Phys. Discuss.: 23 November 2007 \\ Revised: 12 December 2008 - Accepted: 14 December 2008 - Published: 29 January 2009
}

\begin{abstract}
In 1997/1998 a severe smoke episode due to extensive biomass burning, especially of peat, was observed over Indonesia. September 1997 was the month with the highest aerosol burden. This month was simulated using the limited area model REMOTE driven at its lateral boundaries by ERA40 reanalysis data. REMOTE was extended by a new convective cloud parameterization mimicking individual clouds competing for instability energy. This allows for the interaction of aerosols, convective clouds and precipitation. Results show that in the monthly mean convective precipitation is diminished at nearly all places with high aerosol loading, but at some areas with high background humidity precipitation from large-scale clouds may over-compensate the loss in convective rainfall. The simulations revealed that both large-scale and convective clouds' microphysics are influenced by aerosols. Since aerosols are washed and rained out by rainfall, high aerosol concentrations can only persist at low rainfall rates. Hence, aerosol concentrations are not independent of the rainfall amount and in the mean the maximum absolute effects on rainfall from large scale clouds are found at intermediate aerosol concentrations. The reason for this behavior is that at high aerosol concentrations rainfall rates are small and consequently also the anomalies are small. For large-scale as well as for convective rain negative and positive anomalies are found for all aerosol concentrations. Negative anomalies dominate and are highly statistically significant especially for convective rainfall since part of the precipitation loss from large-scale clouds is compensated by moisture detrained from the convective clouds. The mean precipitation from large-scale clouds is less reduced (however still statistically significant) than rain from convective clouds. This effect is due to detrainment of cloud
\end{abstract}

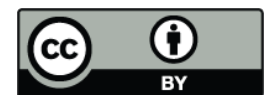

Correspondence to: H.-F. Graf (hfg21@cam.ac.uk) water from the less strongly raining convective clouds and because of the generally lower absolute amounts of rainfall from large-scale clouds. With increasing aerosol load both, convective and large scale clouds produce less rain. At very few individual time steps cases were found when polluted convective clouds produced intensified rainfall via mixed phase microphysics. However, these cases are not unequivocal and opposite results were also simulated, indicating that other than aerosol-microphysics effects have important impact on the results. Overall, the introduction of the new cumulus parameterization and aerosol-cloud interaction reduced some of the original REMOTE biases of precipitation patterns and total amount.

\section{Introduction}

Aerosols and clouds and their non-linear interaction are amongst the biggest challenges in current climate modeling and prediction. Although there is a large number of studies considering aerosol effects on stratiform clouds (for a review see Lohmann and Feichter, 2005), only very recently studies were published discussing effects on convective clouds: Rosenfeld and Woodley (2001), Andreae et al. (2004), Graf (2004), Khain et al. (2004, 2005), Tao et al. (2007), van den Heever et al. (2006) Altaratz et al. (2007). Seifert and Beheng (2006) found different effects of aerosols for different kinds of convective storms. While single cells and super cells reacted to pollution with decreased precipitation, multicell storms produced more precipitation. Van den Heever and Cotton (2007) studied urban pollution and its effect on deep convective clouds. They found (as already suggested by Graf and Graefe (1979) for the effects of Berlin, Germany, on precipitation patterns) that the reduction of precipitation depends on the level of the background aerosol: precipitation

Published by Copernicus Publications on behalf of the European Geosciences Union. 
is diminished in clean background air due to the urban pollution. This effect becomes smaller as the background aerosol load increases. These studies mostly rely on observations and/or cloud resolving models to investigate single cases on a local to regional scale. In contrast, Nober et al. (2003) and Lohmann (2008) discussed the potential effects on global circulation arising from changes in latent heat release, which is due to diminished warm rain formation in the tropics. These effects of anthropogenic aerosols on convective clouds were studied employing the ECHAM5 climate model. In the tropics aerosols from biomass burning are abundant and convection is the prevalent form of precipitation formation (Mori et al., 2004). No further publications are known to the authors on the aerosol effects on warm and mixed phase convective precipitation in large-scale climate or atmospheric models. In current climate models convective clouds are treated by bulk mass flux parameterization excluding explicit cloud microphysical processes. This deficit to a certain degree can be overcome by using cloud-resolving models. However, such models are computationally demanding, what prevents their application in longer-term and large scale climate studies. Very recently Langmann (2007) investigated the effects of aerosol-cloud interaction during the heavy smoke episode around Indonesia in 1997/1998, when the seasonal peat fires ran out of control due to a lack of rain during the El Nino episode. However, Langmann (2007) used the simplistic approach of Nober et al. (2003). This approach does not include explicit cloud microphysics and incorporates only aerosol effects on warm rain, ignoring mixed phase processes. These, however, may lead to non-linear effects (as observed over Amazonia by Andreae et al., 2004 and discussed by Graf, 2004) resulting in a reduction of warm rain where the convective instability is moderate and increased precipitation due to formation of ice where convective instability is large. Over Indonesia, we find a small-scale topography determined by a vast number of smaller and sometimes larger often steep volcanic islands in very warm waters. Therefore, high resolution models are necessary to simulate precipitation reasonably well.

Here we will utilize an alternative approach, suggested by Nober and Graf (2005), to simulate convective clouds in a limited area model. An individual cloud model including explicit cloud microphysics of the warm and of the mixed phase is run with several different initial radii at the cloud base. This convective cloud model has a much higher vertical resolution than the hosting model. By competition of the different individual cloud types for convective available potential energy (CAPE) prescribed by the host model, a specific cloud spectrum evolves at every time step. We will apply this model to September 1997, the month with most severe smoke concentrations over Indonesia and around. This month is characterized by strong pollution from smoke but only weak to moderate atmospheric instability. Our results show that, as observed in single cases over Amazonia (Andreae et al., 2004), the smoke aerosols mostly lead to decreased precipi- tation. Only in very few cases in areas of smoke contamination and concurrent strong atmospheric instability convective precipitation is increased.

\section{Model}

The new convective cloud field model (CCFM) that is based on a concept from population dynamics (Nober and Graf, 2005; Graf and Yang, 2007) has been coupled with the regional atmospheric chemistry model with tracer extension REMOTE (Langmann, 2000). At every grid point and at every time step, first a simplified cloud model is run. We use an entraining parcel, but a more complex cloud model could be used as well. The model is driven by the vertical profiles of temperature and humidity and is initiated by a reasonable set of initial radii and vertical velocities at the cloud base. This provides the spectrum of potential convective clouds. Secondly, the cloud-environment and cloudcloud interaction coefficients are determined and, thirdly, the system is solved under the condition that CAPE is used by the final cloud spectrum as efficiently as possible. This third step provides the final cloud spectrum as a sub-set of the potential clouds from step one. A more complete description of CCFM can be found in Nober and Graf (2005). Originally CCFM was modified and coupled with REMO (the meteorology alone version of REMOTE) for a whole year test over the West Pacific warm pool area, which showed that a simplified CCFM can successfully be used in a limited area model (Graf and Yang, 2007). Our REMOTE-CCFM domain covers Indonesia and the northern part of Australia with a horizontal resolution of 0.5 degrees and 101 grid points in longitude and 55 grid points in latitude. The model was applied with 20 vertical layers of increasing thickness ( $\sigma$-coordinates) between the Earth's surface (see Fig. 1 for isolines of topography) and the $10 \mathrm{hPa}$ pressure level. The model is initialized over the whole grid using ECWMF reanalysis ERA-40 (Uppala et al., 2005) data and then run continuously until the end of the simulation period with an update of the meteorological reanalysis data every $6 \mathrm{~h}$ at the lateral model boundaries only. Two simulations have been carried out for September 1997. In the "control" run only the background CDNC are used and in the "test" run we consider background CDNC plus CDNC resulting from emissions of the wild fires. The model results are stored 6 hourly and the constant time step is $5 \mathrm{~min}$. For our current study the model includes just one tracer, the total particulate matter (TPM) as mass mixing ratio, which can be transported by horizontal and vertical advection, convective processes and vertical diffusion as well as it can be affected by wet and dry deposition. Due to the elevated sulphur content and hygroscopicity of Indonesian vegetation and peat fire aerosols (Langmann and Graf, 2003), particle deposition is calculated as for sulphate. We do not have any information on ice nuclei and therefore cannot take their (potentially important) effects into account. 
The smoke emission estimate uses vegetation and peat maps, remotely sensed fire counts and reports on the total area burned to determine TPM emissions with 0.5 degrees horizontal resolution (Langmann and Heil, 2004). Up to $90 \%$ of the total smoke mass during the catastrophic 1997/1998 fires resulted from burning peat. The weekly smoke emission data from Langmann and Heil (2004) were used and the smoke is released into the first model layer. Freitas et al. (2006) emphasized the need to inject the smoke from Amazonian forest fires at higher elevation. However, Indonesian peat fires are dominated by smoke from relatively cool sources, therefore the release of smoke near the surface is the appropriate approach.

CCFM treats convective clouds as individuals competing for available instability energy. A simplified cloud model (entraining parcel) including explicit (yet simple) cloud microphysics is run at every time step with a number of different initial conditions representing cloud types of different size. The vertical resolution for the cloud model is increased considerably to $70-100 \mathrm{~m}$. For the limited area model REMOTE we cannot apply a large number of different initial cloud types as requested in Nober and Graf (2005) for the use of CCFM in coarse grid models. Instead we use a simplified version of only three cloud types that are different in their initial cloud radius similar as in Graf and Yang (2007): small, medium and large. Thus, the initial set-up of the model is the same as that in the study of Graf and Yang (2007) except that the maximum cloud radius at cloud base is set to $1 / 3$ of the height of the PBL and a slightly modified cloud microphysics scheme was used in order to be able to include effects of the aerosols on cloud microphysics by coupling the rain formation to the aerosol concentration. The cloud base radius of the smallest cloud is set to $r_{\min }=100 \mathrm{~m}$, while the radius of the the biggest cloud is defined as $r_{\max }=1 / 3$ of the PBL height. For the limited area model of 0.5 degree resolution one additional cloud base radius of $\left(r_{\min }+r_{\max }\right) / 2$ is used. For a typical PBL height of $1500 \mathrm{~m}$, the initial cloud base radii would then be $100 \mathrm{~m}, 300 \mathrm{~m}$ and $500 \mathrm{~m}$. In contrast to a recent study by Langmann (2007), who used a modified Tiedtke scheme which only incorporates smoke effects on warm rain formation, switching from high to low autoconversion at a preset limit of CCN concentration, our microphysics scheme also includes mixed phase processes following the parameterizations of Ogura and Takahashi (1971) as described in Nober and Graf (2005). When warm rain formation is suppressed by pollution, the liquid water can be transported above the freezing level, where precipitation formation can be more effective. This potentially allows for an intensification of precipitation in polluted areas where convective instability is high (Andreae et al., 2004; Graf, 2004).

The standard Kessler (1969) parameterization does not allow for the variable width of the initial cloud droplet spectrum at cloud base as it may evolve from aerosol seeding effects. Hence, for the aerosol-cloud interaction studies the auto-conversion formula of Berry (1968) was used in

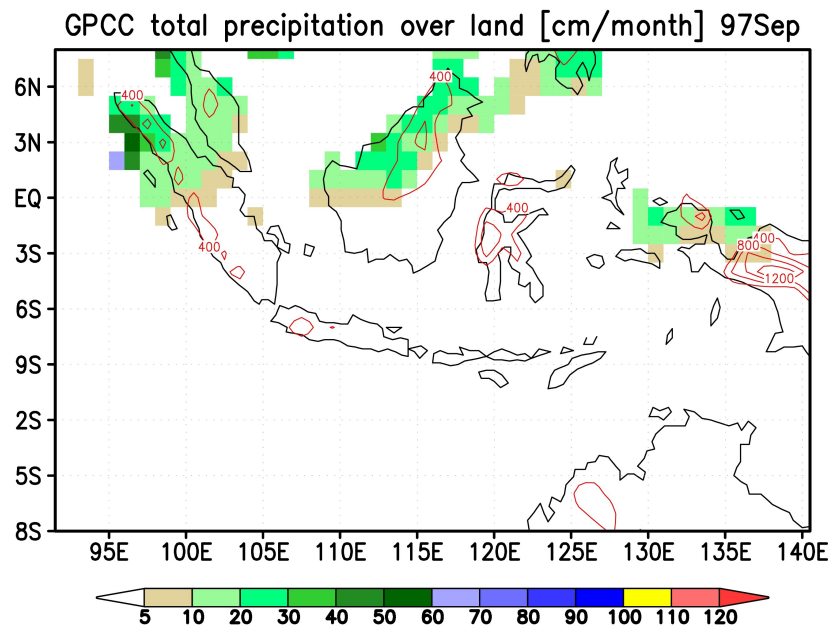

Fig. 1. Precipitation in September 1997 measured by ground-based rain gauges (GPCC: http://www.dwd.de), the red isolines represent topography (in geopotential meters of the surface) as included in the model.

the convective cloud parameterization instead of the original auto-conversion formula of Kessler:

$\frac{d q_{r}}{d t}=\frac{\rho \cdot 10^{3} \cdot q_{l}^{2}}{60\left(5+\frac{0.0366 \cdot N_{b}}{\rho \cdot 10^{3} \cdot q_{l} D_{b}}\right)}$

where $q_{r}$ and $q_{l}$ are precipitation water and cloud liquid water mixing ratio $(\mathrm{kg} / \mathrm{kg})$ respectively, $\rho$ is air density, $N_{b}$ and $D_{b}$ are droplet number density (i.e. CDNC in no.cm ${ }^{-3}$ ) and droplet relative dispersion at the cloud base. $\mathrm{D}_{b}$ is set to standard values: 0.366 over sea and 0.146 over land.

For stratiform clouds a parameterization of the autoconversion rate by Beheng (1994) was included in the latest version of the standard REMOTE model instead of the Sundquist (1978) scheme as it better allows for the introduction of aerosol-microphysics effects (Lohmann and Feichter, 2005):

$d q_{r} / d t=\left(\gamma_{1} \times 6 \times 10^{28} n^{-1.7} N_{l}^{-3.3}\left(10^{-3} \rho q_{l}\right)^{4.7}\right) / \rho$

where $N_{l}$ is the cloud droplet number concentration (CDNC), as above $\rho$ is air density and $\mathrm{q}_{l}$ is cloud water mixing ratio, $\gamma_{1}(=15)$ is a tunable constant which determines the efficiency of rain formation and $n(=10)$ is the width parameter of the initial cloud droplet spectrum described by a gamma function.

From the above parameterizations we know that the formation of precipitation highly depends on cloud droplet number concentration and liquid water content. However, the impact of $\mathrm{CCN}$ on the cloud droplet number concentration is not well constrained due to missing information on aerosol physico-chemical properties. There are two methods that have been used to relate changes in CDNC to changes in aerosol concentrations. These are basically diagnostic (empirical) (Jones et al., 1994; Boucher and Lohmann, 1995) 
and prognostic (mechanistic) parameterizations (Chuang and Penner, 1995; Abdul-Razzak and Ghan, 2000). In this paper we simply used the Boucher and Lohmann (1995) relationship, which is

$$
\mathrm{CDNC}=10^{2.21+0.41 \log (\mathrm{mSO} 4)}
$$

where $\mathrm{mSO} 4$ is the sulphate aerosol mass concentration $\left(\mu \mathrm{g} \mathrm{SO}_{4} \mathrm{~m}^{-3}\right)$ and CDNC is given in $\mathrm{cm}^{-3}$. This estimate from the bulk sulphate mass concentration is a rather rough estimate. We do not have included any effects of ice nuclei and this may influence the clouod dynamics and precipitation yield in mixed clouds. Distinct higher sulfur content was observed in Indonesian peat fire aerosols compared to other vegetation fire aerosols (Gras et al., 1999) and Langmann and Graf (2003) suggested this to be due to accumulated volcanic sulfur. Recent laboratory studies (Dusek et al., 2005) showed that young aerosols resulting from peat fires are very specific in that they form hollow spheres instead of conglomerates as known from other smoke sources. These spheres have limited capacity to act as cloud condensation nuclei. However, it is not yet known how these particles behave when aged. Hence, we conservatively assume that, concerning cloud microphysics, aged peat smoke aerosol acts like organic aerosol, i.e. comparably to sulphate particles, which are very effective cloud condensation nuclei. Thus, we assume for simplicity that $\mathrm{M}_{\mathrm{TPM}}=\mathrm{M}_{\mathrm{SO} 4}$.

In our model region most grid cells are covered by sea, but the potentially large amount of sea salt aerosol is only included in the current model by fixed concentration differences. Following Roeckner (1995) the REMOTE model uses different background CDNC over land and sea: in the planetary boundary layer, up to $850 \mathrm{hPa}$, background $\mathrm{CDNC}=200 \mathrm{~cm}^{-3}$ over land, and $\mathrm{CDNC}=100 \mathrm{~cm}^{-3}$ over sea. In the upper model layers we use $\mathrm{CDNC}=50 \mathrm{~cm}^{-3}$ everywhere. We performed a control run with these background CDNCs and a test run with background CDNC plus CDNC resulting from TPM emissions as simulated interactively by REMOTE-CCFM. We concentrate here on September 1997, the month with the strongest smoke pollution observed during the whole 1997/1998 episode. A more sophisticated treatment of sea salt aerosols would be beneficial since sea salt may produce giant cloud droplets leading to enhanced drizzle and lower humidity remaining in the atmosphere (e.g. Feingold et al., 1999) and sea salt also may affect deep convection (e.g. Laird et al., 2000; van den Heever et al., 2006). Strong dependencies of additional aerosol microphysics effects on the background aerosol have been suggested (e.g. van den Heever and Cotton, 2007; Graf and Graefe, 1979). The effect of enhanced pollution becomes smaller with increasing background pollution. Unfortunately, with the prescribed background CDNC such effects cannot be simulated. We are aware of the fact that our treatment of aerosol microphysics is rather crude compared to specialist models. However, it is much more sophisticated than in nearly all current atmosphere and climate models and it may be seen as a compromise. A more sophisticated treatment of the complexity of aerosols and their interaction with clouds would require a fully coupled chemistry-aerosol-cloud approach that is beyond the scope of this study. However, this study is a step towards that goal showing that the aerosols exert an important effect also on convective clouds.

\section{Results}

In Fig. 1 we show total precipitation as analyzed for September 1997 by the Global Precipitation Climate Center, GPCC, including surface rain gauge results only. This data set probably has a negative bias (Langmann and Heil, 2004) and the observation density is very sparse. Even over land not in every grid box at least one gauge is installed. In Fig. 2 total (top), large scale (or non-convective, middle) and convective (bottom) precipitation are shown for the control run (left column) and the test run with added pollution (middle column) as well as the difference between the two model simulations (right column). Note that the differences are drawn at a smaller scale of $\mathrm{mm} /$ month! The standard REMOTE model containing a bulk mass-flux parameterization for convective clouds from Tiedtke (1989) severely over-estimates precipitation in general and in particular over sea (see Graf and Yang, 2007, their Fig. 8c). The introduction of CCFM (Fig. 2a, see also Fig. 8d in Graf and Yang, 2007) clearly improves the results as already discussed in Graf and Yang (2007). The main precipitation is now simulated as observed over land north of the Equator, but the model overall remains to be wetter than the observations suggest. We would like to emphasize that the main improvements are based on the precipitation patterns. There is no precipitation in the observations south of the Equator, but the control run simulates rainfall over south and central Sumatra and the southern part of Kalimantan. After the introduction of smoke aerosols the test simulation does no longer produce precipitation south of the Equator. We also find a clear reduction of precipitation peaks making the simulated precipitation field smoother. There is the potential of having too much rainfall at some places (like over the high mountains of Irian Jaja), but these also appear in the original versions of REMO and REMOTE and, actually, there do not exist any observations. For a discussion of these effects see Graf and Yang (2007). The inclusion of TPM in the model simulation changes the microphysical structure of the clouds and this leads to a further improvement of the precipitation pattern (Fig. 2b) making it more similar to the observations. The increased precipitation at the westernmost boundary is due to boundary effects. So, overall, REMOTE with CCFM and including TPM provides a very reasonable distribution of precipitation at the height of the dry season over Indonesia and the West Pacific warm pool. The strongest change of precipitation (Fig. 2c) in the simulation including smoke is found over 
(a)

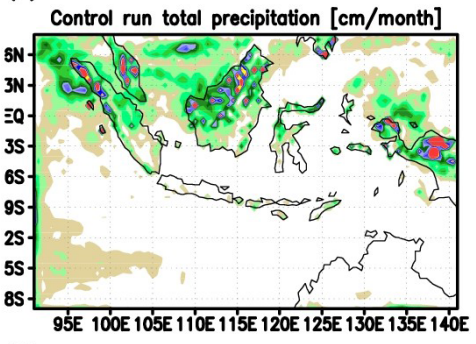

(d)

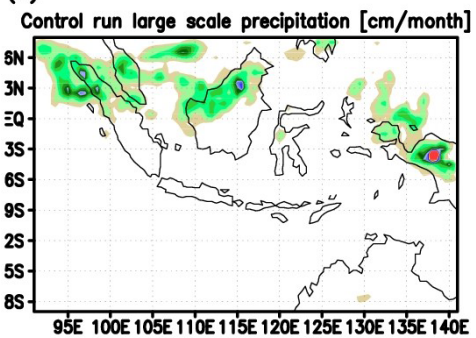

(g)

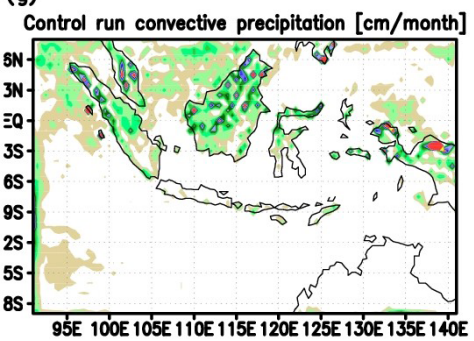

$\int_{8} 10208040800 \% 80100110120$ (b)

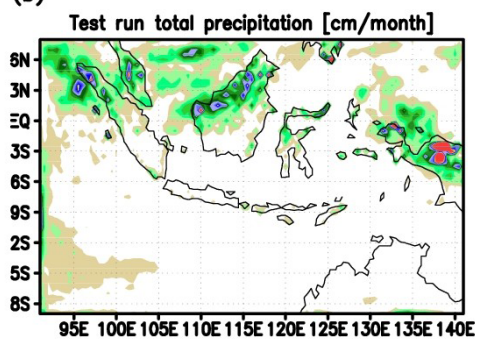

(e)

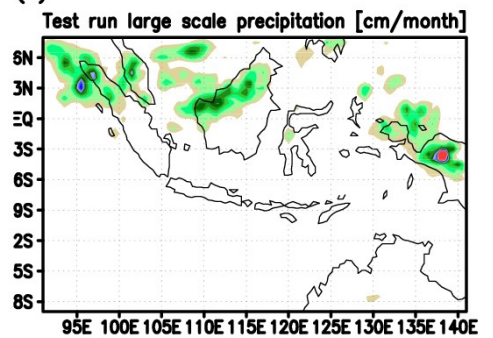

(h)

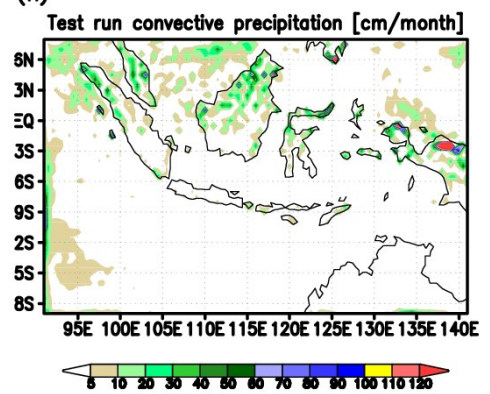

(c)

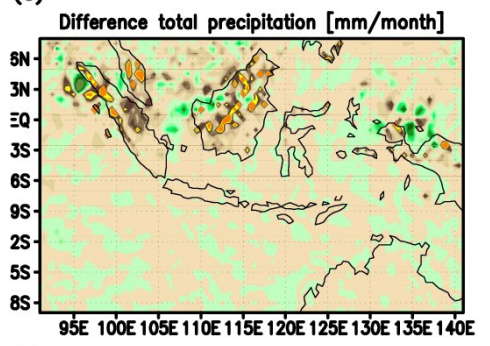

(f)

Difference large scale precipitation [mm/month]

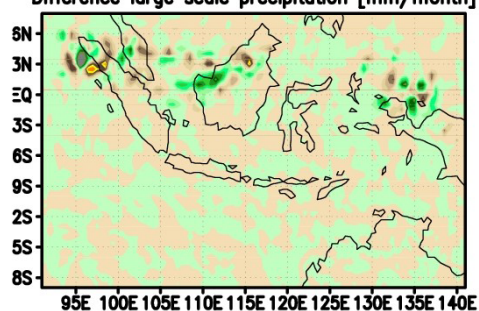

(i)

Difference convective precipitation $[\mathrm{mm} / \mathrm{month}]$

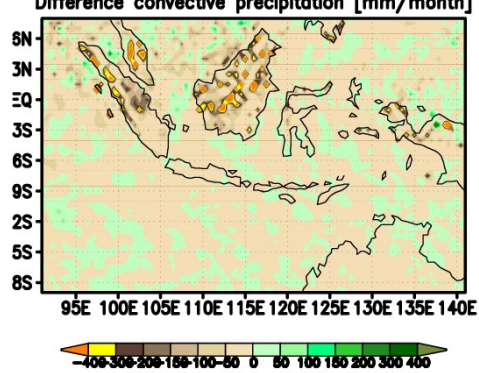

Fig. 2. Precipitation as simulated by REMOTE-CCFM and background CDNC (left column, total, large scale and convective rain from top to bottom), simulated by REMOTE-CCFM and background standard CDNC plus TPM (middle column) and precipitation anomalies between the two simulations (right column). Note that the colors for the differences (right column) are set to mm/month, while the absolute rainfall is in $\mathrm{cm} /$ month.

land (Borneo, North Sumatra, Peninsula Malaysia and West Irian Jaja), where the pollution is strongest. There at most places we see a reduction in total rainfall. This makes the model more consistent with observations.

Table 1 indicates rainfall frequency and amount of convective and large-scale precipitation for ten aerosol concentration classes for the test and the control run. We analyse all latitude-longitude grid points for all days of September 1997 and call these "data points". Note that in the control run the clouds do not "see" the smoke aerosol from the peat fires! We find that very small daily rainfall intensities $(<1 \mathrm{~mm} /$ day $)$ dominate the frequency distribution and that the number of data points having very high pollution by smoke aerosols is quite small. When we only consider total daily rainfall $>1 \mathrm{~mm} /$ day, the percentage of data points with convective rainfall is between $20 \%$ and $30 \%$ with a slight increase in percentage with increasing pollution. This is, however, an indirect effect produced by the fact that most of the strong pollution remains near the sources. These sources are land based and over land convective activity is higher (see also
Fig. 5). In the control run the mean convective rainfall is highest at high aerosol load (except for aerosol class 10) for similar reasons. Basically independent of the aerosol load, convective precipitation is limited to below about $1 \mathrm{~mm}$ /day in the test run for all aerosol classes but the lowest aerosol concentration class one. Hence, the relative loss of convective precipitation increases with increasing aerosol concentration from ca. $70 \%$ at aerosol class 2 to nearly $90 \%$ at aerosol class 9. Large scale precipitation is dominated by rainfall rates $<1 \mathrm{~mm} /$ day and in the control run only at about $10 \%$ of all data points large scale rainfall exceeds $1 \mathrm{~mm} /$ day. This percentage is decreasing towards the highest aerosol concentrations indicating the high efficiency of rain-out and wash-out by large-scale precipitation that does not allow high aerosol concentrations to persist where large scale rainfall is frequent. The mean daily rainfall rates for large scale rain are only slightly higher than $1 \mathrm{~mm} /$ day in the control run, which is much lower than convective rain rates. They decrease with increasing aerosol concentrations for the reasons mentioned above. Hence, it is important to note that rainfall rates and 
Table 1. Basic statistics of rainfall events in the control and test runs for different aerosol concentration classes.

\begin{tabular}{|c|c|c|c|c|c|c|c|c|c|}
\hline \multirow[t]{2}{*}{$\begin{array}{l}\text { Aerosol } \\
\text { classes }\end{array}$} & \multirow[t]{2}{*}{$\begin{array}{l}\text { Total data } \\
\text { points }\end{array}$} & \multicolumn{2}{|c|}{$\begin{array}{l}\text { Relative num. }(>0.0) \\
(\%)\end{array}$} & \multicolumn{2}{|c|}{$\begin{array}{l}\text { Relative num. }(>1.0) \\
(\%)\end{array}$} & \multicolumn{2}{|c|}{$\begin{array}{l}\text { Daily mean convective } \\
\text { rainfall }(\mathrm{mm} / \text { day) } \\
\text { total rainfall in control } \\
>0.0 \mathrm{~m} / \mathrm{d}\end{array}$} & \multicolumn{2}{|c|}{$\begin{array}{l}\text { Daily mean large scale } \\
\text { rainfall (mm/day) } \\
\text { total rainfall in control } \\
>0.0 \mathrm{~m} / \mathrm{d}\end{array}$} \\
\hline & & convective & $\begin{array}{l}\text { large } \\
\text { scale }\end{array}$ & convective & $\begin{array}{l}\text { large } \\
\text { scale }\end{array}$ & control & test & control & test \\
\hline $0.0-0.1$ & 154891 & 58.54 & 94.63 & 14.53 & 8.62 & 1.88 & 1.40 & 1.07 & 1.08 \\
\hline $0.1-0.2$ & 5614 & 68.10 & 100 & 20.47 & 11.54 & 3.32 & 0.98 & 1.07 & 0.86 \\
\hline $0.2-0.3$ & 2255 & 62.75 & 100 & 22.35 & 10.47 & 3.71 & 0.88 & 1.11 & 0.71 \\
\hline $0.3-0.4$ & 1306 & 64.78 & 100 & 22.74 & 9.42 & 3.50 & 0.78 & 0.91 & 0.46 \\
\hline $0.4-0.5$ & 797 & 62.86 & 100 & 27.10 & 10.92 & 4.48 & 0.83 & 0.81 & 0.38 \\
\hline $0.5-0.6$ & 591 & 64.81 & 100 & 23.18 & 9.81 & 5.05 & 0.70 & 0.50 & 0.25 \\
\hline $0.6-0.7$ & 415 & 66.02 & 100 & 26.51 & 9.64 & 5.24 & 1.05 & 0.52 & 0.32 \\
\hline $0.7-0.8$ & 269 & 70.26 & 100 & 28.25 & 5.58 & 6.38 & 0.88 & 0.24 & 0.18 \\
\hline $0.8-0.9$ & 188 & 75.0 & 100 & 29.79 & 6.38 & 7.69 & 0.78 & 0.33 & 0.26 \\
\hline $0.9-1.0$ & 130 & 73.08 & 100 & 26.92 & 2.31 & 4.87 & 0.76 & 0.07 & 0.08 \\
\hline
\end{tabular}

aerosol concentrations are not independent and, thus, also the statistical correlations of aerosols with the amount of rainfall are not solely based on the "over-seeding" effect. In the test run large-scale precipitation is reduced as is convective precipitation, but absolute as well as relative effects are much smaller for large-scale precipitation. The biggest anomalies are simulated for intermediate aerosol loading of classes 3-4. The reason is the very effective rain-out and wash-out process for large-scale precipitation that allows only relatively low aerosol concentrations at high rainfall intensity. Vice versa at high aerosol concentrations rainfall rates are small and therefore the resulting absolute anomalies must be small. This means that in our model simulation over the warm pool area of the West Pacific near the end of the dry season the total effect of aerosols on precipitation is dominated by the effect on convective clouds.

A more complete overview on the mean anomalies and standard deviations of the precipitation anomalies is given in Table 2. Table 2 shows data for convective and largescale precipitation intensity classes and different aerosol column concentration classes. Of these 166650 data points 146580 (90672) have large-scale (convective) precipitation $>0.0 \mathrm{~mm} /$ day and 13356 (22501) exhibit measurable large-scale (convective) precipitation of $>1.0 \mathrm{~mm} /$ day. Even though there are more days with very weak precipitation from large scale clouds, for rainfall intensities $>1 \mathrm{~mm} /$ day precipitation from convective clouds clearly dominates. There are many data points in our model run that have very small aerosol loading and many of these do not have any measurable rainfall. If we include all data points with convective or large scale rainfall $>0 \mathrm{~mm} /$ day in the control run, the anomalies are rather small because of the many data points with very small rainfall $<1 \mathrm{~mm} /$ day (68 171 for convective and 133224 for large-scale rainfall). We will there- fore concentrate our further discussion on data points with at least $1 \mathrm{~mm} /$ day of total rainfall in the control run. This cut-off means that we are only dealing with $\sim 25 \%(\sim 9 \%)$ of the convective (large-scale) rain data points. Most of the negative rainfall anomalies are statistically highly significant according to a t-test. In Table 2 bold, italic and underlined anomaly values indicate statistical significance at a chance of error of $0.1,1$, and $5 \%$, respectively.

Figure 3 (left column) shows the frequency distribution of rainfall anomalies for different rainfall intensity classes (from top downwards: $>0 \mathrm{~mm} /$ day; $>1 \mathrm{~mm} /$ day; $>5 \mathrm{~mm} /$ day; and $>10 \mathrm{~mm} /$ day) between the control run and the test run with increased aerosol load. The data are from all grid points and days that have precipitation of different intensity in the control run and we show the anomalies as test minus control run.

Note that at first we do not consider differences in aerosol concentration across our model domain! It immediately becomes clear from the top left panel of Fig. 3 that most rainfall anomalies are small and remain $<5 \mathrm{~mm} /$ day. It is also obvious that these small anomalies are equally distributed into positive and negative anomalies for large-scale rain, but ca. $60 \%$ are negative and $30 \%$ positive for convective rain. If the very smallest rainfall rates of the control run are excluded (i.e. if we only consider rainfall rates of $>1.0 \mathrm{~mm} /$ day), the frequency of negative anomalies clearly dominates both large-scale and convective rain. The reduction of rainfall, however, is stronger for convective rain. Generally the frequencies of negative (positive) anomalies are higher for convective (large-scale) rain. In total, there are more negative anomalies than positive and this difference is larger for convective rain. Nevertheless we find a considerable contribution of positive rainfall anomalies in the test run with enhanced aerosol load. This may be interpreted as 
Table 2. Mean anomalies and Standard deviations of difference in precipitation between control and test runs and different aerosol classes for different convective and large scale rainfall intensity. Bold, italic and underlined anomaly values indicate $\mathbf{0 . 1}, 1$, and $5 \%$ chance of error according to a t-test.

\begin{tabular}{|c|c|c|c|c|c|c|c|c|c|c|c|c|}
\hline & & & & & Daily & nean aero & ol column & oncentrat & on classes & $\left.\mathrm{g} / \mathrm{m}^{2}\right)$ & & \\
\hline & & Data points & 90672 & 3823 & 1415 & 846 & 501 & 383 & 274 & 189 & 141 & 95 \\
\hline & & STD $(\mathrm{mm})$ & 9.54 & 15.26 & 15.02 & 13.03 & 17.42 & 22.90 & 19.13 & 25.28 & 21.59 & 15.46 \\
\hline$\overline{\widetilde{T}}$ & & Data points & 22501 & 1149 & 504 & 297 & 216 & 137 & 110 & 76 & 56 & 35 \\
\hline . & & Data points & 9310 & 630 & 286 & 168 & 114 & 91 & 65 & 48 & 37 & 20 \\
\hline$\vec{z}$ & $>5.0 \mathrm{~mm} /$ day & Mean (mm) & -10.61 & -21.23 & -22.09 & -20.67 & -24.97 & -27.92 & -26.04 & -31.18 & -34.78 & -25.90 \\
\hline & & STD (mm) & 26.29 & 31.62 & 26.85 & 22.56 & 28.94 & 40.31 & 32.26 & 42.18 & 29.94 & 25.12 \\
\hline & & Data points & 5736 & 425 & 197 & 120 & 87 & 65 & 44 & 38 & 29 & 12 \\
\hline & $>10.0 \mathrm{~mm} /$ day & Mean (mm) & -15.98 & -29.37 & -29.70 & -26.90 & -30.95 & -36.95 & -36.41 & -37.79 & -43.09 & -38.68 \\
\hline & & $\mathrm{STD}(\mathrm{mm})$ & 7.32 & 6.61 & 7.02 & 5.37 & 3.04 & 1.86 & 1.87 & 0.85 & 1.21 & 0.28 \\
\hline 䑢 & & Data points & 13356 & 648 & 236 & 123 & 87 & 58 & 40 & 15 & 12 & 3 \\
\hline 氞 & $>1.0 \mathrm{~mm} /$ day & Mean (mm) & -1.74 & -4.30 & $-\mathbf{5 . 5 7}$ & -6.36 & -4.68 & -2.96 & -2.97 & -2.14 & -1.86 & -1.17 \\
\hline 0 & & $\mathrm{STD}(\mathrm{mm})$ & 21.87 & 15.75 & 19.81 & 15.49 & 7.72 & 4.93 & 4.96 & 2.26 & 4.40 & 0.32 \\
\hline is & & Data points & 4565 & 232 & 85 & 38 & 27 & 11 & 13 & 2 & 2 & - \\
\hline$\stackrel{\mathscr{D}}{*}$ & $>5.0 \mathrm{~mm} /$ day & Mean (mm) & -7.80 & -12.70 & $-\mathbf{1 7 . 8 7}$ & -18.18 & -12.32 & -11.24 & -5.91 & -6.75 & -2.92 & - \\
\hline$\stackrel{\pi}{9}$ & & $\mathrm{STD}(\mathrm{mm})$ & 32.41 & 22.36 & 20.58 & 23.90 & 9.37 & 5.33 & 7.74 & 0.71 & 14.29 & - \\
\hline & & Data points & 2992 & 130 & 55 & 22 & 17 & 7 & 3 & - & - & - \\
\hline & $>10.0 \mathrm{~mm} /$ day & Mean (mm) & -12.78 & -21.42 & -25.35 & -27.32 & -16.43 & -13.68 & -15.04 & - & - & - \\
\hline & & $\mathrm{STD}(\mathrm{mm})$ & 36.89 & 22.84 & 22.04 & 28.16 & 9.36 & 5.11 & 3.40 & - & - & - \\
\hline
\end{tabular}

the result of compensation for convective precipitation loss by increased large scale precipitation (see also below). Also, some of the positive precipitation anomalies from convective clouds may be due to the increase of atmospheric relative humidity resulting from reduced precipitation rather than being due to the switch from decreased to increased precipitation in polluted clouds as reported e.g. by Andreae et al. (2004).

If we additionally consider the aerosol load (Fig. 3, right column), the number of positive anomalies becomes even smaller for both types of rainfall when the aerosol concentration increases and considerable positive rainfall anomalies only occur for large scale rain. For example, for aerosol class 6 about $20 \%$ of all anomalies are positive and $<5 \mathrm{~mm} /$ day but only $6 \%$ (8 individual cases) are positive for convective rain. However, the positive convective rain anomalies can be considerably larger in individual cases as will be discussed at the end of the Results section.

The mean aerosol column concentration (TPM) for September 1997 (Fig. 4a) resulting from the interaction of smoke emission, transport and wet and dry deposition is sim- ilar to the concentrations presented by Langmann (2007). There are maxima clearly adjacent to the burning peat areas over South Sumatra, South Borneo and parts of Irian Jaja. Application of Eq. (3) to the aerosol concentration at all model levels for the control and for the test runs reveals the differences in column cloud droplet number, Fig. 4b. As expected, these differences are largest where the aerosol concentrations are highest. The pattern of the cloud droplet column concentration very well matches the aerosol concentration. However, as seen from Fig. 4c, the strongest anomalies in liquid water path of all, convective plus large-scale clouds are not strictly matching either the aerosol concentration or cloud droplet concentrations. Over Borneo the strongest positive anomaly in liquid water path is found in the North, i.e. downwind of the highly polluted area and it is similar over Sumatra. In general, over the whole model domain we see an increase in liquid water path except at some randomly scattered places. Hence, the increased aerosol concentration leading to increased cloud droplet concentration (both in convective and large-scale clouds) and reduced rainfall 

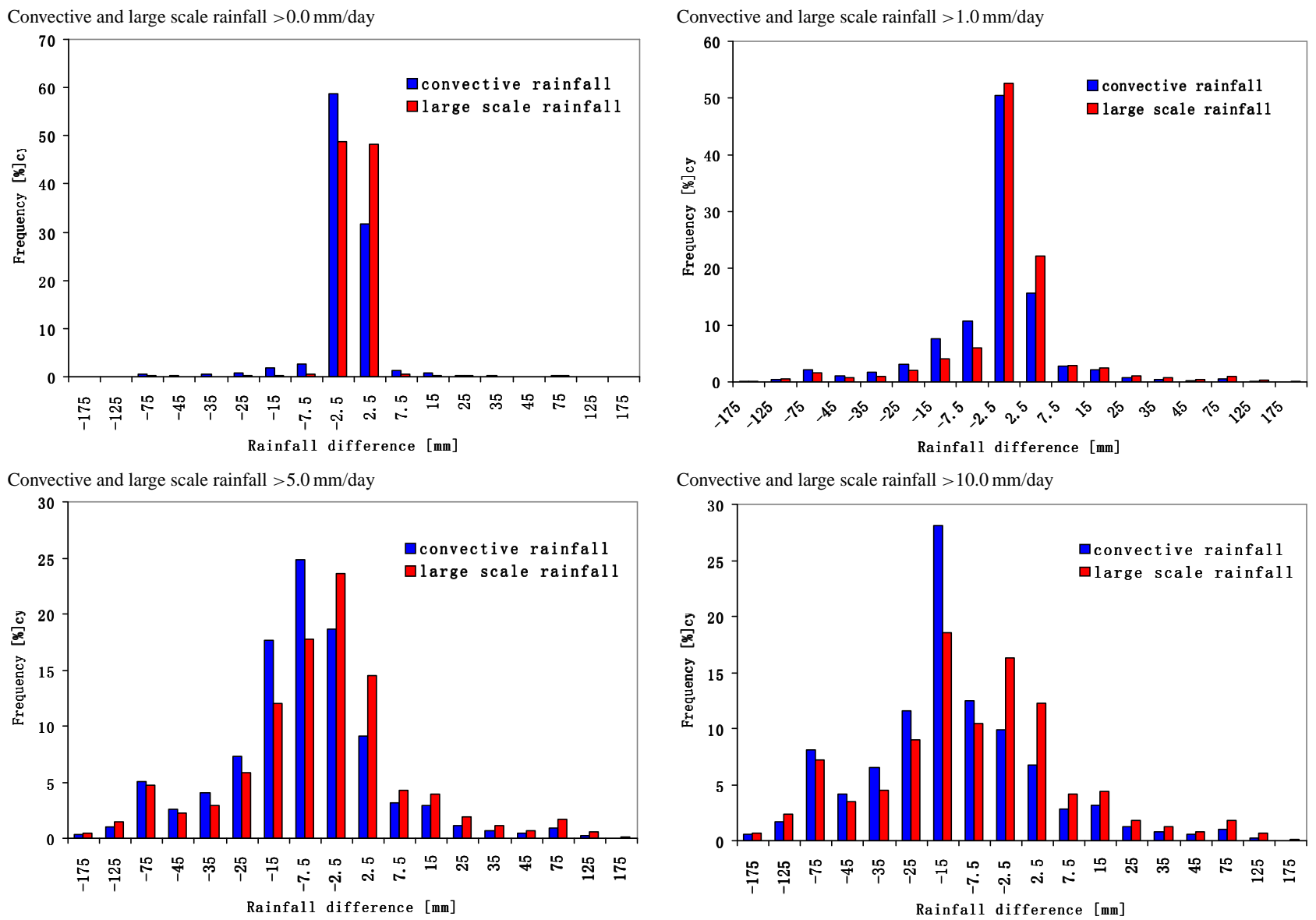

Fig. 3. Frequencies of rainfall anomalies between the test run and the control run with increased aerosol load in different rainfall intensity regimes (this page, from top down: $>0.0 \mathrm{~mm} /$ day, $>1 \mathrm{~mm} /$ day; $>5 \mathrm{~mm} /$ day; and $>10 \mathrm{~mm} /$ day) and for different aerosol concentration classes (class 1: $0.0-0.1 \mathrm{~g} / \mathrm{m}^{2}$, class 4: $0.3-0.4 \mathrm{~g} / \mathrm{m}^{2}$, class $6: 0.5-0.6 \mathrm{~g} / \mathrm{m}^{2}$ and class $8: 0.8-0.9 \mathrm{~g} / \mathrm{m}^{2}$ from top down, next page).

formation leads to clouds with higher liquid water content. These clouds are optically thicker. Only where the water vapor supply in undisturbed conditions is already very high (these are often those areas which have high large scale rainfall in the control run) the effect can be opposite. When precipitation formation is reduced in convective clouds due to additional condensation nuclei under high background relative humidity, the remaining cloud water of these clouds is detrained into their environment, thus raising the relative humidity of the ambient air. Since the formation of large-scale clouds depends on relative humidity, they become more abundant and contain more cloud water. If the large scale cloud water content is high enough, precipitation sets in and this may compensate some of the loss of precipitation by convective clouds. Therefore, over most of the model area the particle mass column concentration is slightly increased when the pollution effects are included in the convective cloud microphysics (Fig. 4d). Rainout is depressed due to the suppression of warm rain formation in the most polluted areas. Only at some places, most prominent in the Northwest of Borneo, fewer particles are found in the air. There, while convective precipitation is decreased, total precipitation is increased significantly by enhanced largescale rainfall (Fig. 2f) leading to more efficient rainout of the aerosols. At this point we would like to stress that it is impossible to decide, based on the current structure of all regional and global circulation models, whether the effect of compensation of convective precipitation loss by increased large-scale precipitation is a model artifact or not. All models split clouds and precipitation into the categories large-scale (which is basically dependent on the mean relative humidity in a grid cell) and convective. The subroutine for convective clouds and precipitation is called first and its results feed the subroutine for large-scale clouds and precipitation. Hence, the compensation process is inherent in the model structure. If it works the same way in reality remains an open question until dedicated observations are available. The only way to avoid this operator splitting in the models is to use a cloud resolving process model, but this is computationally prohibitively demanding. In studies 


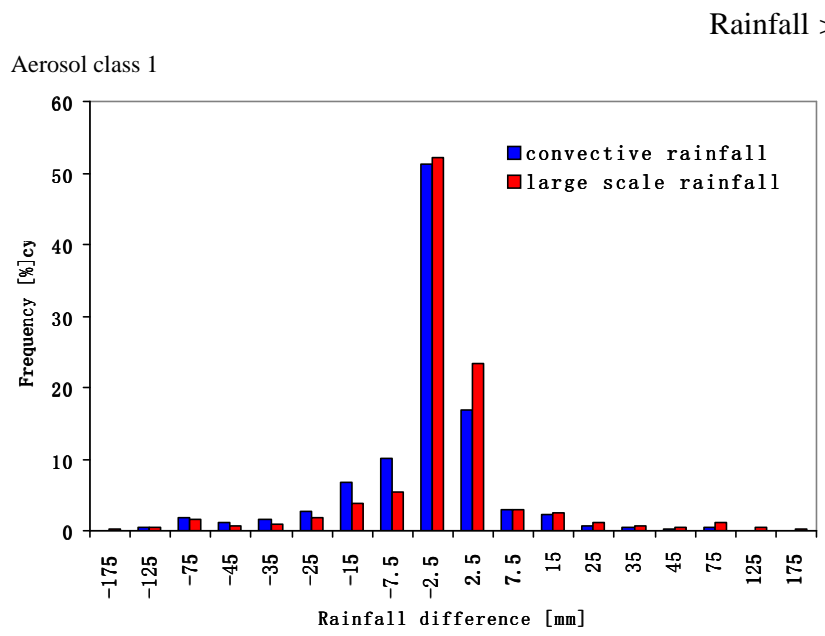

Aerosol class 6
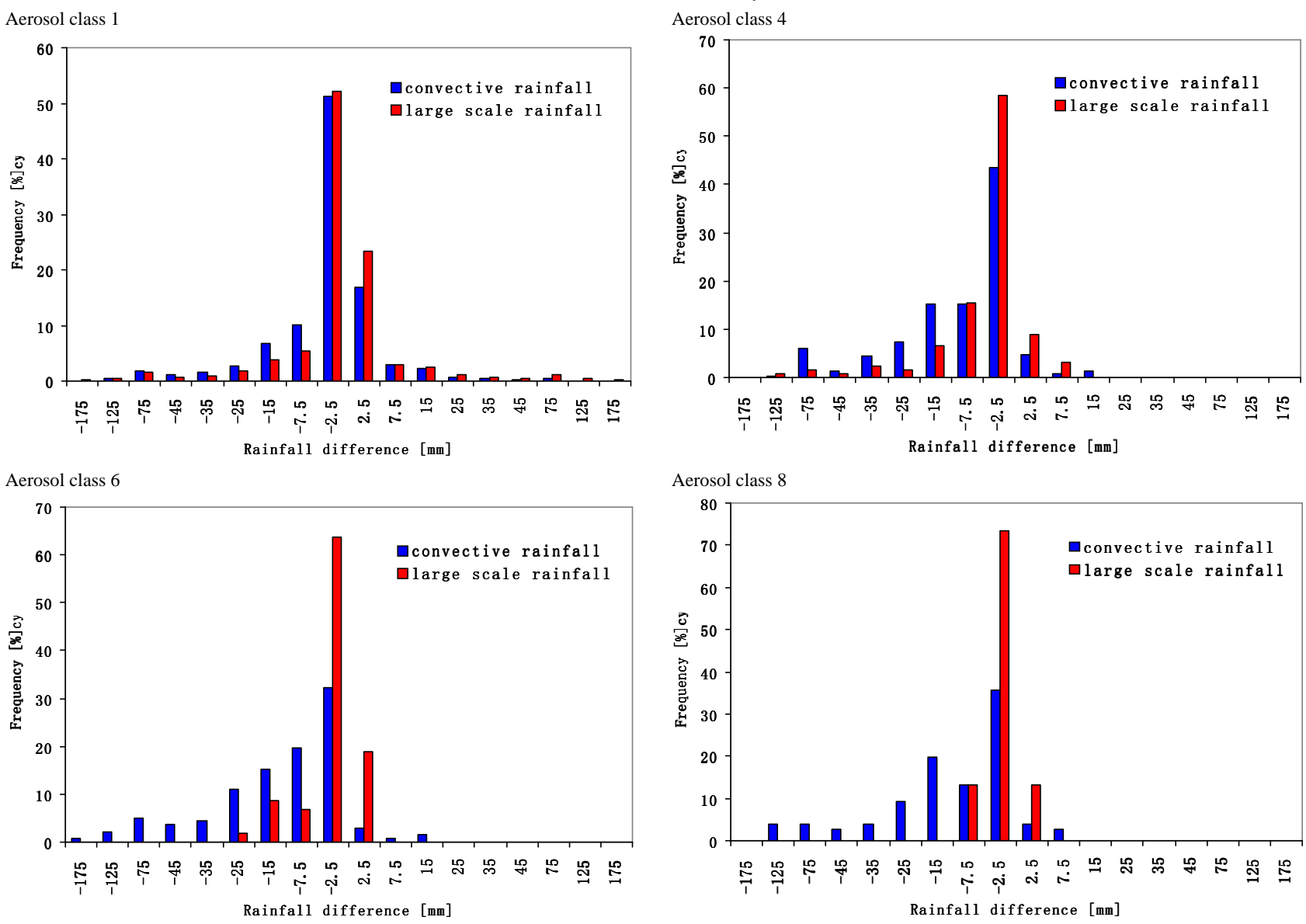

Aerosol class 8

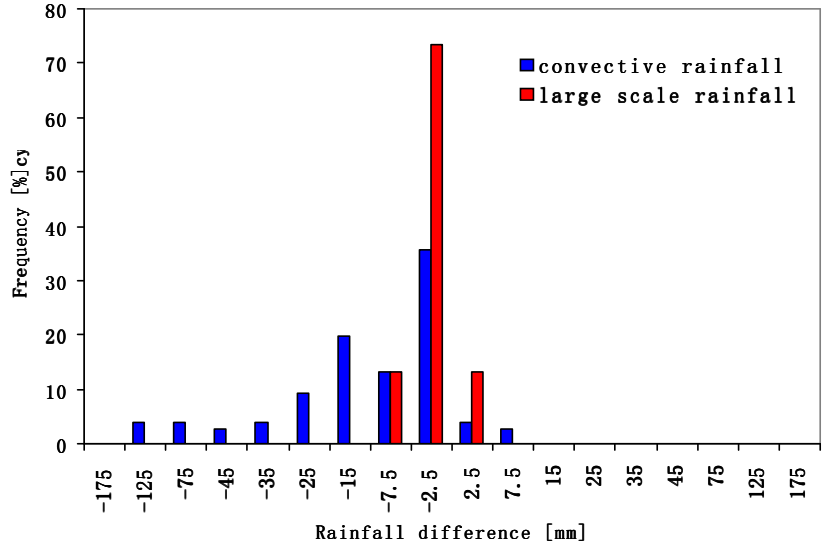

Fig. 3. Continued.

where only aerosol effects in large-scale clouds were considered (see the review by Lohmann and Feichter, 2005) this compensation mechanism does not work and a reduction of large-scale precipitation and an increase of cloud water content (with all the effects on radiative properties of the largescale clouds) is simulated. Our results suggest that it is necessary to recalculate the aerosol indirect effects on cloud radiative properties with convective clouds included.

Overall, although our model still seems to be moister than the sparse observations suggest, the precipitation pattern simulated including smoke particle effects is much closer to surface observations. Total precipitation is reduced (Fig. 2b) compared with the run in which only background CDNC were used (Fig. 2a) at most places where the aerosol load is large. However, there are some extended areas next to these areas of reduced total precipitation where rainfall is substantially increased. These we find mainly over northwest Borneo and the Strait of Malacca and to the west of the northern tip of Sumatra as well as near the northern coast of Irian Jaja, always to the North of the most polluted areas, downwind from the highest pollution. As Fig. $2 \mathrm{f}$ indicates, these areas of increased total precipitation are due to heavier large-scale rainfall over-compensating for reduced convective rainfall (Fig. 2i). One reason for this behavior is that in the model, when convective precipitation is diminished, the remaining water vapor is transported downwind and is added to the humidity used for the calculation of large-scale precipitation. This may lead to excessive large-scale rain in the moistest areas. These are also areas of increased aerosol load and so it is of interest what kind of clouds produced these differences. Over land convective precipitation is decreased in all areas in which heavy pollution occurs (Fig. 2i), while over sea some slight increase in convective precipitation is also seen in polluted areas, e.g. Strait of Malacca and northern Sumatra Strait. However, these clouds rarely reach altitudes in which freezing takes part in the formation of rainfall. On the other hand, where rainfall is most depressed it is the biggest clouds whose height is reduced, while smaller ones, mainly over Sumatra, are higher than in the reference experiment.

The increase of monthly mean cloud heights is generally not large (in most cases only 200 to $400 \mathrm{~m}$ ). However, this 

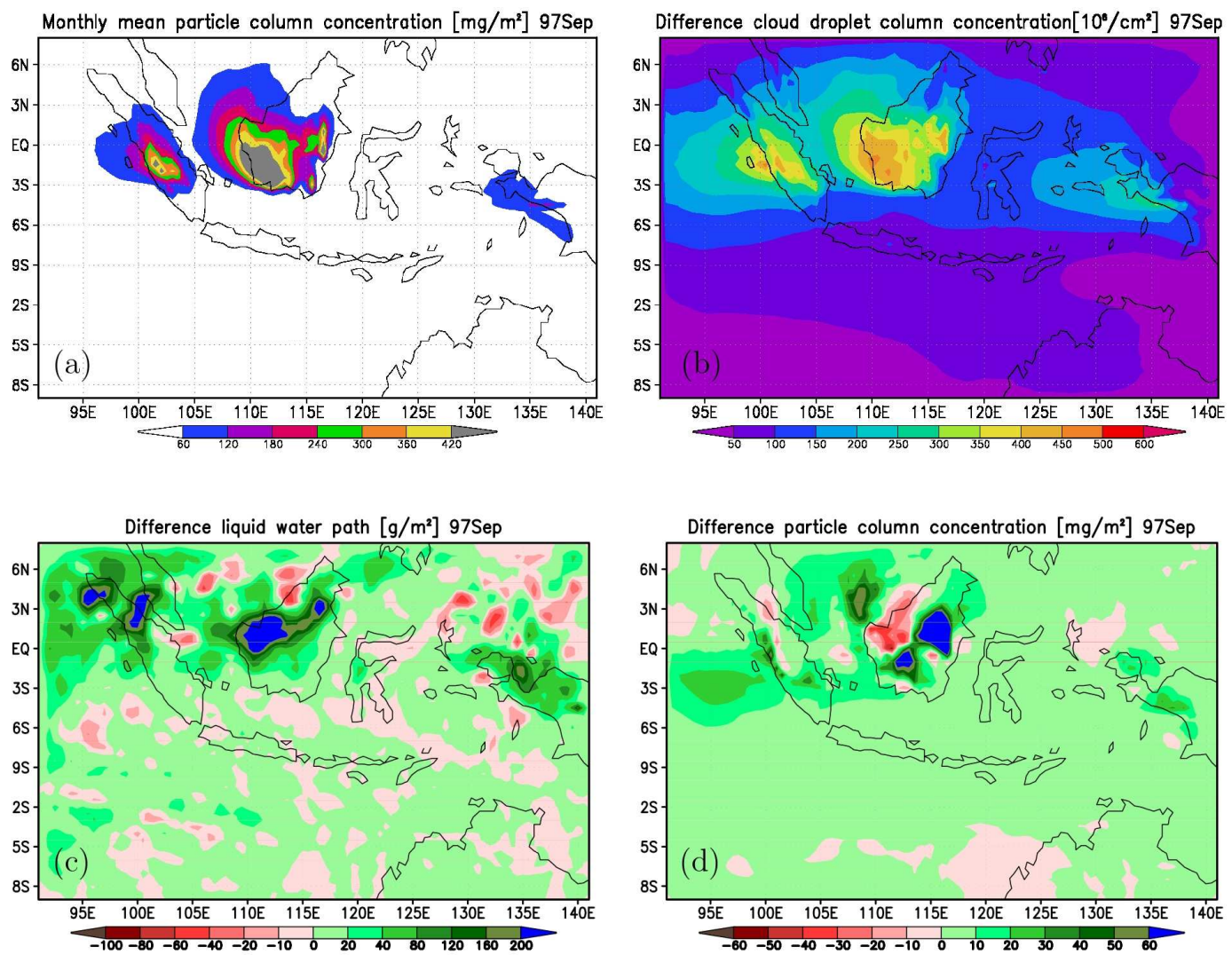

Fig. 4. Differences between REMOTE-CCFM simulations with additional smoke aerosols and without. (a) monthly mean particle column concentration, (b) cloud droplet concentration, (c) liquid water path, (d) particle column concentration.

picture changes when we look into more detail. In Fig. 5 time step data of atmospheric instability as measured by Convective Available Potential Energy (CAPE), cloud top temperature of the biggest cloud type, and convective precipitation for the runs including TPM plus background CDNC and only background CDNC are compared. This comparison was performed for two distinct areas of four model grid points each, one in the Sumatra Strait (longitude $108.0^{\circ} \mathrm{E}$ to $108.5^{\circ} \mathrm{E}$, latitude $1.0^{\circ} \mathrm{N}$ to $1.5^{\circ} \mathrm{N}$ ), where total precipitation is slightly enhanced and another over South Kalimantan $\left(111.0^{\circ} \mathrm{E}\right.$ to $111.5^{\circ} \mathrm{E}$, latitude $0.5^{\circ} \mathrm{N}$ to $1.0^{\circ} \mathrm{N}$ ), where precipitation is strongly reduced. September is at the high of the dry season in Indonesia, so CAPE is generally small most of the time with just a few extreme events. Even though the limited area model is forced every six hours by lateral boundary conditions from ECMWF reanalysis ERA40, weather as measured by CAPE may be very different around similar time steps in the polluted and non-polluted cases. This shows the modulating effect of the additional aerosol on atmospheric stability and weather. Hence it is not easy to make direct comparisons. CAPE in the mean is slightly higher and more variable over land than over sea. The cloud top temperatures nearly always remain above the main freezing level of cloud droplets $\left(-15^{\circ} \mathrm{C}\right)$ and as expected they are more variable and lower over land. Strong rainfall from convective clouds does not develop often over land and even less over sea. There is just one prominent case in the polluted atmosphere over the Sumatra Strait when CAPE leads to a much enhanced cloud height with cloud top temperature well below the freezing level and heavier convective precipitation than in the clean case (Fig. 5, right column, time step $\sim 8400$ ). In two cases CAPE is much stronger in the clean case, leading to much higher convection and rainfall being produced only by the clean cloud (time steps $\sim 600$ and 1700). Over land (Fig. 5, left) we find another case (time step 7800) in the polluted environment in which CAPE is enhanced and convective precipitation is stronger, but the clean cloud, although producing less rain, rises higher. The opposite happens at the beginning of the month (time step 1500) when the opposite happens, i.e. CAPE is enhanced in the clean simulation and so are cloud height and precipitation. In yet another case (time step 1700), with enhanced CAPE in the polluted as well as in the clean simulation and cloud top temperature well below the freezing level, the model produces no convective precipitation. These individual results indicate that there is no regular and simple effect based on a combination of strong CAPE, low cloud top temperature and aerosol-microphysics effects alone that might produce regularly enhanced convective precipitation if the mixed phase state of the polluted convective cloud is reached. 

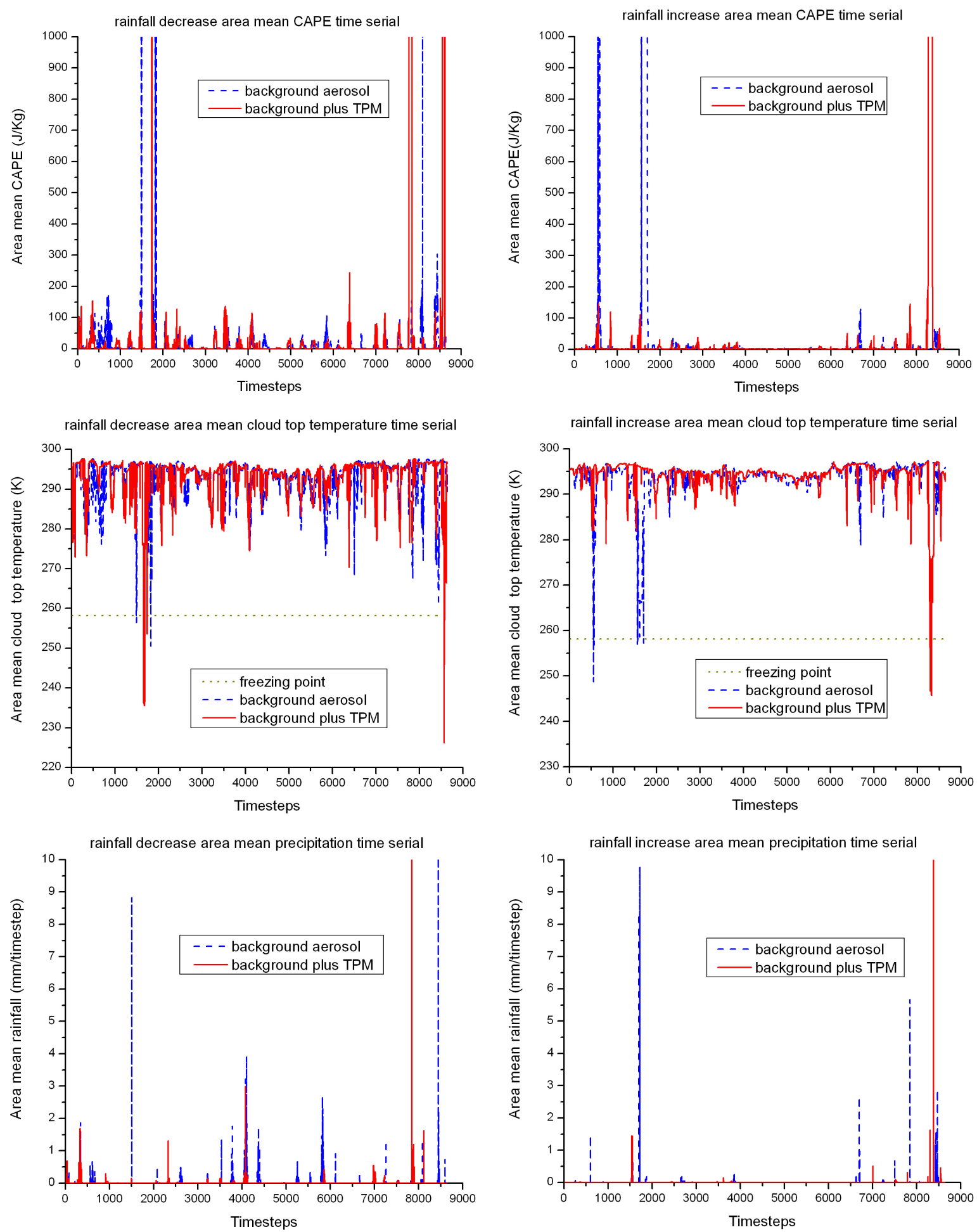

Fig. 5. Examples of individual time step results for one area with decreasing total precipitation (left column, situated over South Kalimantan) and one with increasing total precipitation (right column, over the Sumatra Strait). Shown are (from top down): area mean CAPE, area mean cloud top temperature, and area mean convective rainfall. 


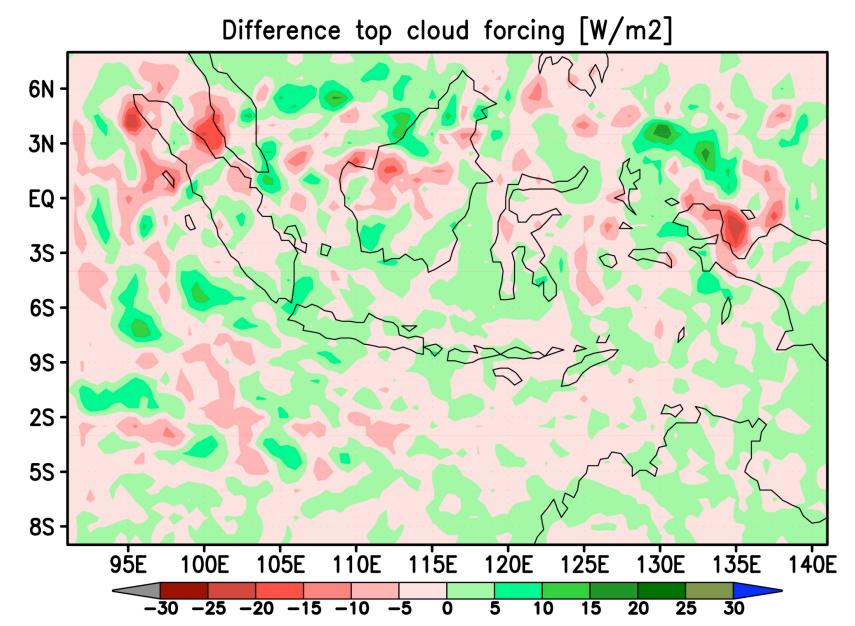

Fig. 6. Monthly mean difference between the runs with and without inclusion of TPM of top of the atmosphere total cloud radiative forcing.

If a statistical effect linking CAPE or cloud top height to aerosol effects on precipitation existed, extensive analysis under varying conditions would have to be performed to investigate it. This would also require a multi-dimensional statistical analysis including the probability density functions of precipitation intensity under varying parameters such as CAPE, TPM (including certain thresholds), cloud top temperature, cloud size etc. Such a study requires a better representation of cloud microphysics. At least a twomoment scheme is needed to simulate the aerosol effects on CDNC. Freezing temperatures would have to depend on droplet chemistry and size. In addition some information on activation of ice nuclei would be necessary. All this remains to be a future project.

The cloud radiative forcing at the top of the atmosphere (Fig. 6) is dominated by shortwave forcing and is generally negative due to the brightening of the clouds. The long wave forcing is in general positive, but smaller. The total negative forcing is damped where the clouds are significantly higher, leading to less outgoing long wave radiation. The area mean radiative forcing is negative but small and remains in the order of $-0.7 \mathrm{~W} / \mathrm{m}^{2}$. At some places, like over the seas adjacent to northern Sumatra, over West Borneo and just to the north of Irian Jaja negative local values of -10 to $-20 \mathrm{~W} / \mathrm{m}^{2}$ are reached.

\section{Concluding discussion}

We have applied a limited area model including internal explicit convective cloud treatment to a case study of much enhanced smoke pollution mostly from peat fires in Indonesia, September 1997. This specific episode is of interest due to the extreme pollution and occasional precipitation, which suggests that aerosol-microphysics effects should be rele- vant. Aerosols and clouds, both convective and large scale, were treated interactively and, for the first time, microphysical processes were included for warm and mixed phase rainfall formation not only in large scale but also in convective clouds. Our results show that, although the monthly mean rainfall is depressed over most of the heavily polluted areas, there are coherent areas, which are also also polluted, where the opposite is the case. These areas are situated downwind of those locations where convective precipitation is suppressed and occur mainly over or in proximity to the sea, where moisture supply is high. Langmann (2007) also found individual $6 \mathrm{~h}$ intervals in her simulation of the same case during which precipitation was enhanced over generally polluted areas. However, only considering the warm phase rainfall, she produced an overall reduction of rain in the monthly mean over the whole model domain. Although it would be possible in principle that the increased rainfall is produced in our model due to moisture that is detrained from the clouds that had suppressed rainfall in the last time step, this process would generate a highly noisy pattern in space and time. With the clear patterns simulated by the model, however, we may rule out this model-internal shift of precipitation between time steps. Instead we observe a shift from convective to large-scale rainfall especially where the moisture level of the atmosphere is already high in the background simulations. Our results show that it is feasible to include a parameterization of explicit convective clouds including aerosol-microphysics effects in the style of the CCFM (Nober and Graf, 2005) also in a limited area model. The resulting monthly precipitation pattern is closer to the (limited) observations when aerosol effects on convective clouds are considered. So far it is clear that warm convective rain is suppressed in polluted air masses and that part of this deficit can be made up by large-scale precipitation, sometimes it can even be over-compensated. We see a stronger reduction of convective rainfall in the mean while large-scale rainfall exhibits less frequent negative anomalies and overall is less reduced. This is due to the compensation mechanism inherent in all models known to us. Since large-scale clouds are those most relevant for radiative transfer in climate models, we suggest that it is necessary to investigate the reality of compensation between convective and large scale clouds and to re-investigate the effects of aerosols on large scale clouds as summarized in Feichter and Lohmann (2005). Since mixed phase microphysics might be important for the non-linear switch from depressed to increased convective rainfall, it is very important to also include information on ice nuclei in aerosol-cloud models. Lacking these is one of the main deficits of our current simulations. In addition, higher moment microphysics will be necessary to better simulate aerosol effects on droplet formation and growth. Only then the right height (initial freezing temperature) of the switch in rainfall regimes will be detectable. This poses a big challenge to aerosol modelers, which has not yet been met. Since there is no simple relation between aerosols 
and precipitation at ground, complex statistical studies are required to investigate the changes in PDF for rainfall intensity depending on pollution level and vertical profiles of temperature, winds and moisture. More case studies of observed precipitation and pollution will be necessary and our model still needs tuning to avoid it being overly moist. However, the results obtained so far encourage us to perform further studies including the above mentioned process parameterizations and also to include the convective transport of chemical species (soluble and insoluble) in the near future.

Edited by: U. Lohmann

\section{References}

Abdul-Razzak, H. and Ghan, S.: A parameterization of aerosol activation 2, Multiple aerosol types, J. Geophys. Res., 105, 68376844, 2000.

Andreae, M. O., Rosenfeld, D., Artaxo, P., et al.: Smoking rain clouds over the Amazon, Science, 303, 1337-1342, doi:10.1126/science.1092779, 2004.

Altaratz, O., Koren, I., Reisin, T., Kostinski, A., Feingold, G., Levin, Z., and Yin, Y.: Aerosols' influence on the interplay between condensation, evaporation and rain in warm cumulus cloud, Atmos. Chem. Phys., 8, 15-24, 2008, http://www.atmos-chem-phys.net/8/15/2008/.

Beheng, K. D.: A parameterization of warm cloud microphysical conversion processes, Atmos. Res., 33, 193-206, 1994

Berry, E. X.: Modification of the warm rain process, Proc. First Natl. Conf. Weather Modification, Ed. American Meteorological Society, State University of New York, Albany, 81-88, 1968.

Boucher, O. and Lohmann, U.: The sulphate-CCN-cloud albedo effect - A sensitivity study with two general circulation models, Tellus, 47B, 281-300, 1995.

Chuang, C. C. and Penner, J. E.: Effects of anthropogenic sulphate on cloud drop nucleation and optical properties, Tellus, 47, 566577, 1995.

Dusek, U., Frank, G. P., Helas, G., et al.: "Missing" cloud condensation nuclei in peat smoke, Geophys. Res. Lett., 32, L11802, doi:10.1029/2005GL022473, 2005.

Feingold, G., Cotton, W. R., Kreidenweis, S. M., and Davis, J. T.: The impact of giant condensation nuclei on drizzle formation in stratocumulus: Implications for cloud radiative properties, J. Atmos. Sci., 56, 24, 4100-4117, 1999.

Graf, H.-F. and Gräfe, I.: Die Niederschlagsverteilung im Raum Berlin in Abhängigkeit von Höhenwetterlage und Bodenwindrichtung, (The distribution of precipitation in the Berlin area depending on height weather and surface wind direction), Z. Meteorol., 29, 56-64, 1979.

Graf, H.-F.: The complex interaction of aerosols and clouds, Science, 203, 1309-1311, 27 February 2004.

Graf, H.-F. and Yang, J.: Evaluation of a new convective cloud field model: precipitation over the maritime continent, Atmos. Chem. Phys., 7, 409-421, 2007,

http://www.atmos-chem-phys.net/7/409/2007/.

Gras, J. L., Jensen, J. B., Okada, K., Ikegami, M., Zaizen, Y., and Makino, Y.: Some optical properties of smoke aerosol in Indone- sian and tropical Australia, Geophys. Res. Lett., 26, 1393-1396, 1999.

Jones, A., Roberts, D. L., and Slingo, A.: A climate model study of indirect radiative forcing by anthropogenic aerosols, Nature, 370, 450-453, 1994.

Kessler, E.: On the distribution and continuity of water substance in atmospheric circulation models, Metero. Monographs, Amer. Meteor. Soc., Boston, MA, 10(32), 84 pp., 1969.

Khain, A., Rosenfeld, D., and Pokrovsky, A.: Aerosol impact on the dynamics and microphysics of deep convective clouds, Q. J. Roy. Meteor. Soc., Part: A, 131, 611, 2639-2663, 2005.

Khain, A. and Pokrovsky, A.: Simulation of effects of atmospheric aerosols on deep turbulent convective clouds using a spectral microphysics mixed-phase cumulus cloud model, Part II: Sensitivity study, J. Atmos. Sci., 61, 24, 2983-3001, 2004.

Laird, N. F., Ochs, H. T., Rauber, R. M., et al.: Initial precipitation formation in warm Florida cumulus, J. Atmos. Sci., 57, 22, 3740-3751, 2000.

Langmann, B.: Numerical modelling of regional scale transport and photochemistry directly together with meteorological process, Atmos. Environ., 34, 3585-3598, 2000.

Langmann, B.: A model study of smoke-haze influence on clouds and warm precipitation formation in Indonesia 1997/1998, Atmos. Environ., 41, 6838-6852, 2007.

Langmann, B. and Graf, H.-F.: Indonesian smoke aerosols from peat fires and the contributiuon from volcanic sulfur emissions, Geophys. Res. Lett., 30, 1547-1550, 2003.

Langmann, B. and Heil, A.: Release and dispersion of vegetation and peat fire emissions in the atmosphere over Indonesia 1997/1998, Atmos. Chem. Phys., 4, 2145-2160, 2004, http://www.atmos-chem-phys.net/4/2145/2004/.

Lohmann, U. and Feichter, J.: Global indirect aerosol effects: a review, Atmos. Chem. Phys., 5, 715-737, 2005, http://www.atmos-chem-phys.net/5/715/2005/.

Lohmann, U.: Global anthropogenic aerosol effects on convective clouds in ECHAM5-HAM, Atmos. Chem. Phys., 8, 2115-2131, 2008, http://www.atmos-chem-phys.net/8/2115/2008/.

Mori, S., Hamada, J.-I., Tauhid, Y.I., Yamanaka, M.D., Okamoto, N., Murata, F., Sakurai, N., Hashiguchi, H., and Sribimawati, T.: Diurnal Land-Sea Rainfall Peak Migration over Sumatera Island, Indonesian Maritime Continent, Observed by TRMM Satellite and Intensive Rawinsonde Soundings, Mon. Weather Rev., 132, 2021-2039, 2004.

Nober, F. J. and Graf, H. F.: A new convective cloud field model based on principles of self-organisation, Atmos. Chem. Phys., 5, 2749-2759, 2005, http://www.atmos-chem-phys.net/5/2749/2005/.

Ogura, Y. and Takahashi, T.: Numerical simulation of the life cycle of a thunderstorm cell, Mon. Weather Rev., 99, 895-911, 1971.

Roeckner, E.: Parameterization of cloud radiative properties in the ECHAM4 model, In WCRP workshop "Cloud microphysics parameterizations in global atmospheric circulation models", 23 35 May 1995, WCRP=90, Kananskis, Canada, 105-116, 1995.

Seifert, A. and Beheng, K. D.: A two-moment cloud microphysics parameterization for mixed-phase clouds, Part II: Deep convective storms, Meteorol. Atmos. Phys., 92, 67-82, doi:10.1007/s00703-005-0113-3, 2006.

Sundquist, H.: A parameterization scheme for non-convective condensation including prediction of cloud water content, Q. J. Roy. 
Meteor. Soc., 104, 677-690, 1978.

Tao, W. K, Li, X. W., Khain, A., Matsui, T., Lang, S., and Simpson, J.: Role of atmospheric aerosol concentration on deep convective precipitation: Cloud-resolving model simulations, J. Geophys. Res.-Atmos. 112, D24S18, doi:10.1029/2007JD008728, 2007.

Tiedtke, M.: A comprehensive mass flux scheme for cumulus cloud parameterisation in lagre-scale models, Q. J. Roy. Meteor. Soc., 117, 1779-1800, 1989.
Uppala, S. M., Kallberg, P. W., Simmons, A. J., et al.: The ERA-40 re-analysis, Q. J. Roy. Meteor. Soc., 131, 2961-3012, 2005.

van den Heever, S. C., Carrio, G. G., Cotton, W. R., DeMott, P., and Prenni, A. J.: Impacts of Nucleating Aerosol on Florida Storms, Part I: Mesoscale Simulations, J. Atmos. Sci., 63(7), 1752-1775, 2006.

van den Heever, S. C. and Cotton, W. R.: Urban Aerosol Impacts on Downwind Convective Storms, J. Appl. Meteorol. Clim., 46(6), 828-850, 2007. 